\title{
DESPONTE DOS RAMOS DA VIDEIRA E SEU EFEITO NA QUALIDADE DOS FRUTOS DE 'MERLOT' SOBRE OS PORTA-ENXERTOS 'PAULSEN 1103’ E ‘COUDERC 3309’’
}

\author{
ALBERTO FONTANELLA BRIGHENTI², LEO RUFATO ${ }^{3}$, \\ AIKE ANNELIESE KRETZSCHMAR ${ }^{4}$, FILIPE CAMARGO MADEIRA ${ }^{5}$
}

RESUMO - A produção de uvas viníferas nas regiões de altitude do Estado de Santa Catarina é recente e existem poucos dados de pesquisa sobre o comportamento das diferentes cultivares neste local. Os objetivos do trabalho foram testar o efeito de diferentes níveis de desponte do dossel vegetativo e avaliar a influência de dois porta-enxertos nas características dos frutos produzidos. O experimento foi realizado em São JoaquimSC (28¹7’38” S e 4955’54” W), a uma altitude média de 1.250 m, na Vinícola Villa Francioni, com a cultivar Merlot enxertada em 'Paulsen 1103' e 'Couderc 3309'. Os tratamentos consistiram no desponte em diferentes níveis, mantendo as áreas foliares de 4,5; 2,5; 2,0 e 1,5 $\mathrm{m}^{2} \mathrm{~kg}^{-1}$ de uva em dois porta-enxertos. Foram avaliados número de bagas por cacho, diâmetro de bagas, $\mathrm{pH}$, sólidos solúveis totais, antocianinas, índice de polifenóis totais, comprimento e peso de cacho. As plantas enxertadas em 'Paulsen 1103' apresentaram a máxima eficiência para o nível de desponte de $3,4 \mathrm{~m}^{2} \mathrm{~kg}^{-1} \mathrm{de}$ uva, já as plantas enxertadas sobre 'Couderc 3309' apresentaram a máxima eficiência com a manutenção de uma área foliar de 3,0 $\mathrm{m}^{2} \mathrm{~kg}^{-1} \mathrm{de}^{\mathrm{d}}$ uva. Os diferentes porta-enxertos não interferiram nos compostos fenólicos dos frutos. No ciclo de 2005/06, Couderc 3309 produziu frutos com maiores teores de sólidos solúveis totais e, no ciclo de 2006/07, produziu cachos mais pesados.

Termos para Indexação: Vitis vinifera L., poda verde, manejo da copa.

\section{SHOOT TOPPING ON MERLOT GRAPEVINES GRAFTED ON PAULSEN 1103 AND COUDERC 3309 AND ITS EFFECTS ON THE QUALITY OF GRAPES}

\begin{abstract}
The production of grapevines in regions of high altitude of Santa Catarina state is recent and there are few data on the behavior of different cultivars. The objective of this work was to verify the effect of different levels of shoot topping and evaluate the influence of two rootstocks on the characteristics of the fruit produced. The experiment was conducted in the city of São Joaquim, Santa Catarina state (28¹7’38” $\underline{\mathrm{S}}$ and 49 55'54” W), in an altitude of 1.250m, at Villa Francioni Vineyards, with Merlot grapevine grafted on Paulsen 1103 and Couderc 3309. The treatments consisted in different levels of shoot topping, keeping the leaf area of $4.5 ; 2.5 ; 2.0$ and $1.5 \mathrm{~m}^{2} \mathrm{~kg}^{-1}$ of grapes in two rootstocks. The variables evaluated were: number of berries per bunch, berry diameter, $\mathrm{pH}$, total soluble solids, anthocyanins, total polyphenols index, length and weight of the bunch. Plants grafted on Paulsen 1103 showed the maximum efficiency maintaining a leaf area of $3.4 \mathrm{~m}^{2} . \mathrm{kg}^{-1}$ of grapes, while plants grafted on Couderc 3309 showed the maximum efficiency maintaining a leaf area of $3.0 \mathrm{~m}^{2} \cdot \mathrm{kg}^{-1}$ of grapes. The rootstocks did not present difference for the phenolic compounds. In the 2005/06 cycle, plants grafted on Paulsen 1103 produced the largest berries, but with lower content of total soluble solids. In the 2006/07 cycle, plants grafted on Couderc 3309 produced heavier bunches.

Index terms: Vitis vinifera L., summer pruning, canopy management.
\end{abstract}

\footnotetext{
${ }^{1}$ (Trabalho 069-09). Recebido em: 23-03-2009. Aceito para publicação em: 20-11-2009.

${ }^{2}$ Engenheiro Agrônomo, mestrando Produção Vegetal CAV-UDESC; Av. Luiz de Camões 2090, Bairro Conta Dinheiro, Lages-SC, CEP: 88520-000 brighenti_07@hotmail.com

${ }^{3}$ Orientador, Dr. Fruticultura, Professor CAV/UDESC, leoruffato@yahoo.com.br

${ }^{4}$ Orientadora, Dra. Fruticultura, Professora CAV/UDESC, a2aak@cav.udesc.br

${ }^{5}$ Engenheiro Agrônomo, mestrando Recursos Genéticos e Vegetais CCA-UFSC, ficamadeira@gmail.com
} 


\section{INTRODUÇÃO}

A viticultura tradicional no Estado de Santa Catarina caracteriza-se por apresentar, em sua maior parte, a produção de uvas híbridas e americanas, mais bem adaptadas às condições climáticas destas zonas de produção (Bonin \& Brighenti, 2005). Atualmente, novas regiões de produção estão surgindo em zonas de altitude acima de 1.000 metros, nos municípios de São Joaquim, Água Doce e Campos Novos.

A partir do ano de 2000, houve expansão expressiva da vitivinicultura em regiões de altitude, como é o caso da região de São Joaquim, onde a altitude elevada $(1.200$ a $1.400 \mathrm{~m})$, aliada à baixa latitude, proporciona deslocamento de todo o ciclo produtivo da videira, que se caracteriza por duas situações distintas em seus extremos. Por um lado, as baixas temperaturas noturnas retardam o início da brotação. Enquanto, no outro extremo do ciclo vegetativo, na maturação, as temperaturas noturnas amenas retardam o amadurecimento dos frutos, reduzem o crescimento das plantas e influenciam no metabolismo. O resultado é que a colheita ocorre em um período onde, historicamente, os índices pluviométricos são menores que nos meses de colheita das regiões tradicionalmente produtoras, o que permite a maturação fenólica mais completa (Bonin \& Brighenti, 2006).

O desponte dos ramos, que retira mais de 30 cm terminais, é uma prática comum em uvas viníferas, cujo vigor não foi controlado por outras práticas de manejo, para conter a copa em suas dimensões preestabelecidas e manter a luminosidade. $\mathrm{O}$ desponte estimula a emissão e o crescimento de feminelas em todo o ramo, muitas vezes prejudicando o microclima da copa. Sua finalidade é limitar o crescimento vegetativo mediante a eliminação de partes de ramos herbáceos. O usual é fazer o desponte duas vezes na temporada, deixando o número adequado de nós com folhas (Intrieri \& Poni, 1995; Intrieri et al., 1995; Reynolds et al., 2005; Mandelli et al., 2008).

Em condições normais, o desponte recomendado é de apenas $30 \mathrm{~cm}$ terminais no período de mudança de cor das bagas, sem produzir muito crescimento de feminelas, o que elimina apenas as folhas consumidoras Martinez de Toda (1982).

Em vinhedos vigorosos, essa prática melhora a penetração de luz na planta e a qualidade do vinho, porém com atraso na maturação da uva e da lignificação dos brotos (Gil \& Pszczólkowski, 2007). Em zonas frias, recomenda-se o desponte precoce dos ramos para aumentar a insolação nos cachos e para induzir o surgimento de novas folhas (Koblet, 1987).
A qualidade da uva, e consequentemente do vinho são resultados da interação de aspectos biológicos, físicos, climáticos, sanitários e culturais (Silva et al., 2008).

Porta-enxertos são usados em vinhedos desde a segunda metade do século XIX, como consequência da invasão da filoxera (Daktulosphaira vitifoliae). Primariamente, os porta-enxertos foram utilizados como forma de resistência ao ataque de pragas, mas hoje eles são utilizados como adaptação a determinadas condições climáticas, diferentes tipos de solo, controle de pragas e doenças de solo (Machado et al., 2005; Pinkerton et al., 2005).

Dentro de certos limites, porta-enxertos que promovem aumento no grau de crescimento vegetativo têm efeito positivo na produtividade, ao afetar o tamanho da baga e a composição química da fruta, como o conteúdo de açúcares, de ácidos orgânicos e de antocianinas, determinando a composição do vinho (Reynolds \& Wardle, 2001; Ollat et al., 2003). Na maioria dos casos, é difícil estabelecer se as mudanças na composição da fruta se devem, diretamente, ao acúmulo de metabólitos ou, indiretamente, às diferenças de vigor, de produtividade ou de arquitetura da copa (Main et al., 2002; Clímaco et al., 2003).

O objetivo deste trabalho foi avaliar o efeito de diferentes níveis de desponte do dossel vegetativo, na maturação fenólica e nas características dos frutos da uva cv. Merlot, enxertada nos porta-enxertos Paulsen 1103 e Couderc 3309.

\section{MATERIAL E MÉTODOS}

O experimento foi realizado na cidade de São Joaquim, no Estado de Santa Catarina (28¹7'38' S e 4955’54” W), nos vinhedos da Vinícola Villa Francioni, situados a uma altitude média de $1.250 \mathrm{~m}$. Avaliou-se a cultivar Merlot, enxertada sobre 'Paulsen 1103' e 'Couderc 3309'. As plantas foram conduzidas no sistema espaldeira, com 4 anos de idade, no espaçamento de 3,0 x 0,75 m. A poda de inverno foi realizada em cordão esporonado, deixando-se em média duas gemas por esporão. A carga das plantas foi determinada pela empresa e ficou em torno de 9 ton $\mathrm{ha}^{-1}$, e para atingir essa produtividade foram deixados em torno de 12 cachos por planta e sempre um cacho por ramo. Os tratamentos foram realizados no momento de mudança de cor das bagas.

O desponte foi realizado nos dias 9 de janeiro de 2006 e 22 de janeiro de 2007, utilizando os seguintes tratamentos: testemunha, sem realização de desponte, mantendo uma área foliar de $4,5 \mathrm{~m}^{2} \mathrm{~kg}^{-1}$ 
de uva (Figura 1A). Desponte no quarto arame do sistema de condução, a 1,25 m do cordão esporonado, mantendo-se uma área foliar de $2,5 \mathrm{~m}^{2} \mathrm{~kg}^{-1}$ de uva (Figura 1B). Desponte na metade do terceiro arame, a 1,03 m do cordão esporonado, mantendo-se uma área foliar de 2,0 $\mathrm{m}^{2} \mathrm{~kg}^{-1}$ de uva (Figura 1C). Desponte no terceiro arame, a 0,8 $\mathrm{m}$ do cordão esporonado, com uma área foliar de $1,5 \mathrm{~m}^{2} \mathrm{~kg}^{-1}$ de uva (Figura 1D).

A área foliar foi determinada a partir da amostragem de 50 folhas retiradas do vinhedo. A área média dessas folhas foi determinada com o folharímetro. Após a implantação dos tratamentos de desponte, as folhas remanescentes foram contadas, e seu número foi multiplicado pela área média das folhas coletadas anteriormente.

As análises foram realizadas no Núcleo de Tecnologia de Alimentos, do Centro de Ciências Agroveterinárias da Universidade do Estado de Santa Catarina (CAV - UDESC), em Lages - SC. As varáveis teor de antocianinas, índice de polifenóis totais e teor de sólidos solúveis totais foram avaliadas para os diferentes níveis de desponte, sendo esses dados submetidos à análise de regressão polinomial. As variáveis número de bagas por cacho, diâmetro de bagas, $\mathrm{pH}$, sólidos solúveis totais, teor de antocianinas, índice de polifenóis totais, comprimento e peso de cacho foram utilizadas para avaliar o efeito do porta-enxerto nas características dos frutos, e foram analisadas pelo teste de Tukey, a 5\% de probabilidade de erro. $\mathrm{O}$ delineamento experimental utilizado foi o de blocos ao acaso, com 4 repetições e 8 plantas por parcela.

Para determinar a concentração dos compostos fenólicos, utilizou-se uma subamostra de 50 bagas. As sementes foram retiradas para evitar uma leitura superestimada, atribuída aos taninos duros, contidos no seu interior e não extraídos durante o processo de vinificação. Seguindo metodologia descrita por Iland et al. (2004), utilizou-se uma solução hidroalcoólica de etanol a $50 \% \mathrm{v} \mathrm{v}^{-1}$, ajustada a $\mathrm{pH}$ 2, simulando a extração das antocianinas e polifenóis totais durante a fermentação alcoólica da vinificação. Essas condições, somadas à agitação constante e ao aquecimento em banho-maria, por cinco minutos, extraem aproximadamente $94 \%$ dos compostos fenólicos e é chamada de solução-extrato.

A quantificação do aporte fenólico das bagas foi baseada na metodologia proposta por Glories (1998) e Ribéreau-Gayon et al. (1998), através da absorbância característica do ciclo benzênico, componente da maior parte dos polifenóis. Utilizou-se 1 $\mathrm{mL}$ de solução-extrato diluído em $100 \mathrm{~mL}$ de água destilada e realizou-se a leitura em espectrofotômetro. Calculou-se a absorbância do comprimento de onda de $280 \mathrm{~nm}$ em uma cubeta de quartzo de 10,01 $\mathrm{mm}$ de percurso óptico, mediante a fórmula IPT = D.O.280*f (Fator de diluição).

A concentração de antocianinas extraíveis foi estimada segundo a metodologia proposta por Ribéreau-Gayon et al. (1982), método químico baseado na propriedade característica das antocianinas, as quais variam sua cor de acordo com o $\mathrm{pH}$.

\section{RESULTADOS E DISCUSSÃO}

Na variável índice de polifenóis totais (Figura 2), observou-se que, no ciclo de 2005/06 (Figura 2A), seus valores aumentaram até a área foliar de 3,1 $\mathrm{m}^{2} \mathrm{~kg}^{-1}$ de uva, para depois diminuir no porta-enxerto 'Couderc 3309'. Entretanto, para 'Paulsen 1103', observou-se comportamento inverso. $\mathrm{O}$ ponto de mínimo foi atingido na área foliar de 3,4 $\mathrm{m}^{2} \mathrm{~kg}^{-1}$ de uva. Já, no ciclo de 2006/07 (Figura 2B), os porta-enxertos comportaram-se de maneira semelhante. Os índices de polifenóis decresceram até uma área foliar de $3,25 \mathrm{~m}^{2} \mathrm{~kg}^{-1}$ de uva, no 'Paulsen 1103', e a 3,5 $\mathrm{m}^{2} \mathrm{~kg}^{-1}$ de uva, no 'Couderc 3309' para, a partir desses pontos, aumentar. $\mathrm{O}$ índice de polifenóis totais depende de vários fatores, como a safra, o clima, o grau de maturação da uva, o status hídrico, a nutrição mineral, a época de colheita e a sanidade da uva (Fregoni, 1998). A média histórica de precipitação em São Joaquim-SC, do período de janeiro a abril, momento de mudança de cor das bagas à colheita, é de $515 \mathrm{~mm}$. Na safra de 2005/06, a precipitação esteve abaixo da média, com 303,9 $\mathrm{mm}$, praticamente a metade da precipitação da safra de 2006/07, que foi de 591,6 mm (Ficagna, 2008). É possível afirmar que o comportamento dos porta-enxertos foi afetado pelo status hídrico da planta, na safra de 2005/06, e que, nessa condição atípica e desejada de baixa umidade, o porta-enxerto 'Couderc 3309', quando submetido aos tratamentos de desponte, apresentou desempenho superior ao atingido no 'Paulsen 1103’ para a variável índice de polifenóis totais.

Observou-se, no ciclo de 2005/06 (Figura 3A), que os valores de antocianinas aumentaram até atingir seu máximo nas áreas foliares de 3,4 e 3,14 $\mathrm{m}^{2} \mathrm{~kg}^{-1}$ de uva, para 'Paulsen 1103' e 'Couderc 3309', respectivamente. No ciclo de 2006/07 (Figura 3B), os valores das antocianinas aumentaram até as áreas foliares de 3,0 $\mathrm{m}^{2} \mathrm{~kg}^{-1}$ de uva, para 'Paulsen 1103', e $2,5 \mathrm{~m}^{2} \mathrm{~kg}^{-1}$ de uva, para 'Couderc 3309'. Fregoni (1998) cita que as práticas culturais que estimulam o vigor da planta não são favoráveis ao acúmulo de 
substâncias corantes, porque atrasam o processo de maturação, desviando os produtos da fotossíntese para a síntese proteica. O vigor estimula, de maneira considerável, a competição entre a atividade vegetativa e a atividade reprodutiva da planta. Na videira, há uma fonte de síntese que é a folha e dois drenos principais, o ápice vegetativo e os cachos. É possível observar que o desponte equilibrou a relação fontedreno da planta, direcionando os fotoassimilados para os cachos.

Ainda em relação às antocianinas, o vigor influencia de maneira notável na respiração. Um ramo vigoroso possui atividade respiratória muito elevada, de modo que o consumo de energia é maior que em ramos de médio a reduzido vigor, nos quais há maior equilíbrio entre fotossíntese e respiração. Plantas mais equilibradas acumulam nas bagas maiores quatidades de carboidratos, que são precursores das antocianinas. Enquanto ramos vigorosos produzem maiores quantidades de carboidratos, também os consomem em maior quantidade, para manter o crescimento vegetativo (Fregoni, 1998; Gil \& Pszczólkowski, 2007).

No ciclo de 2005/06 (Figura 4A), observase, para ambos os porta-enxertos, que os teores de sólidos solúveis totais aumentaram até atingir seu máximo nas áreas foliares de $3,4 \mathrm{~m}^{2} \mathrm{~kg}^{-1}$ de uva, para 'Paulsen 1103', e 3,1 $\mathrm{m}^{2} \mathrm{~kg}^{-1}$ de uva, para 'Couderc 3309', e, a partir desses pontos, começaram a decrescer. No ciclo de 2006/07 (Figura 4B), o porta-enxerto 'Paulsen 1103 ' teve comportamento semelhante ao ciclo anterior, mas 'Couderc 3309' apresentou um comportamento linear, já que os valores dos sólidos solúveis totais reduziram com o aumento da área foliar. Para Fregoni (1998), o acúmulo de açúcar é uma etapa muito importante da maturação, não apenas porque dele deriva o álcool, mas também porque o açúcar é precursor de muitos outros compostos, como polifenóis, antocianinas e aromas. Quando o ramo é vigoroso, resulta em maior atração das substâncias nutritivas em direção ao ápice vegetativo, enquanto isso, o cacho permanece com pouco aporte de substâncias nutritivas, e seu desenvolvimento completo ou sua maturação ficam prejudicados (Fregoni, 1998). A desfolha excessiva também é prejudicial, pois reduz o aporte de carboidratos para os cachos, comprometendo o seu desenvolvimento.

A brotação excessiva de feminelas não foi detectada nos dois anos em que o experimento foi conduzido, confirmando os resultados obtidos por Toda (1982), porque essa operação foi realizada durante o período de mudança de cor das bagas e porque as temperaturas nas regiões de altitude de
Santa Catarina começam a baixar na fase de amadurecimento da uva.

No ciclo de 2005/06, observou-se que as plantas enxertadas em 'Paulsen 1103' apresentaram bagas de maior diâmetro, e as plantas enxertadas em 'Couderc 3309' produziram frutos de maior teor de sólidos solúveis totais; para as demais variáveis, não houve diferença estatísitca significativa (Tabela 1). Jackson \& Lombard (1993) sugerem que os efeitos dos porta-enxertos na composição da uva são, provavelmente, dependentes do vigor do porta-enxerto e, consequentemente, sua influência na expansão da copa e na exposição da fruta. Em um ciclo com menor precipitação pluviométrica, como foi 2005/06, o porta-enxerto 'Paulsen 1103', mais vigoroso, garantiu maior absorção de águas para as plantas e, dessa forma, produziu bagas de maior tamanho e com menor teor de açúcar.

No ciclo de 2006/07, as plantas enxertadas em 'Couderc 3309' produziram cachos mais pesados que as plantas sobre 'Paulsen 1103'. As demais variáveis não apresentaram diferença estatística significativa (Tabela 2). Nas regiões de altitude de Santa Catarina, a produção da uva Merlot pode ser irregular, porque esse cv. possui problemas de frutificação, que se acentuam com baixas temperaturas e chuvas durante o período de floração. $\mathrm{O}$ aumento dos peso dos cachos pode ser associado a uma melhoria no percentual de frutificação efetiva. May (2004) observou que alguns porta-enxertos, como o 'Couderc 3309’, 101-14, 44-53, 420 A, 1616 C e 5C, aumentam a frutificação, enquanto 'Paulsen 1103', 161-49 e ‘Gravesac’ não apresentaram efeitos. 


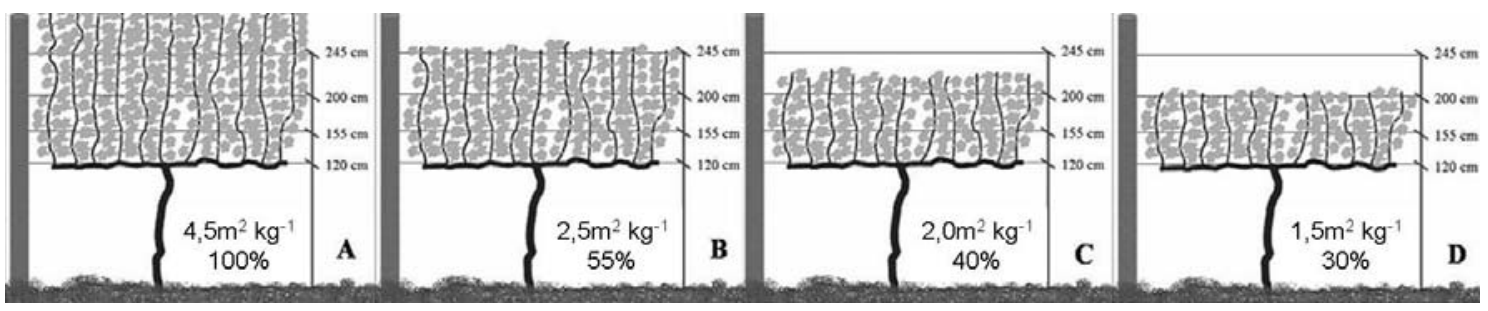

FIGURA 1 - Representação dos diferentes manejos do dossel vegetativo. Testemunha, sem realização de desponte (A), desponte no quarto arame do sistema de condução, a 1,25 m do cordão esporonado (B), desponte na metade do terceiro arame, a 1,03 m do cordão esporonado (C), desponte no terceiro arame, a 0,8 m do cordão esporonado (D). Lages-SC, 2008.
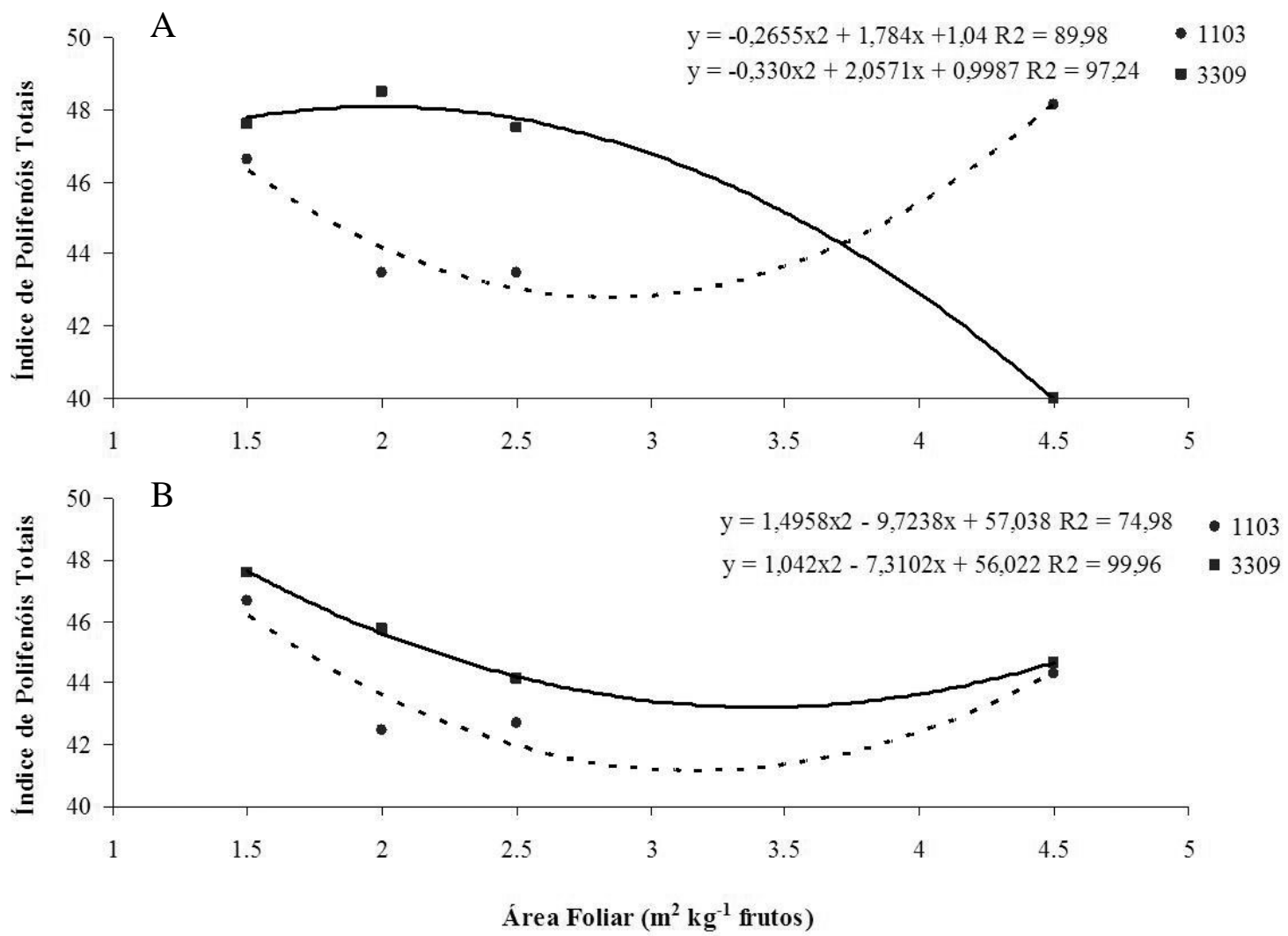

FIGURA 2 - Variação do índice de polifenóis totais (IPT) da uva Merlot (Vitis vinifera L.) sobre os portaenxertos 'Paulsen 1103” e 'Couderc 3309' submetida a diferentes níveis de desponte, nos ciclos de 2005-2006 (A) e 2006-2007 (B). Lages-SC, 2008. 

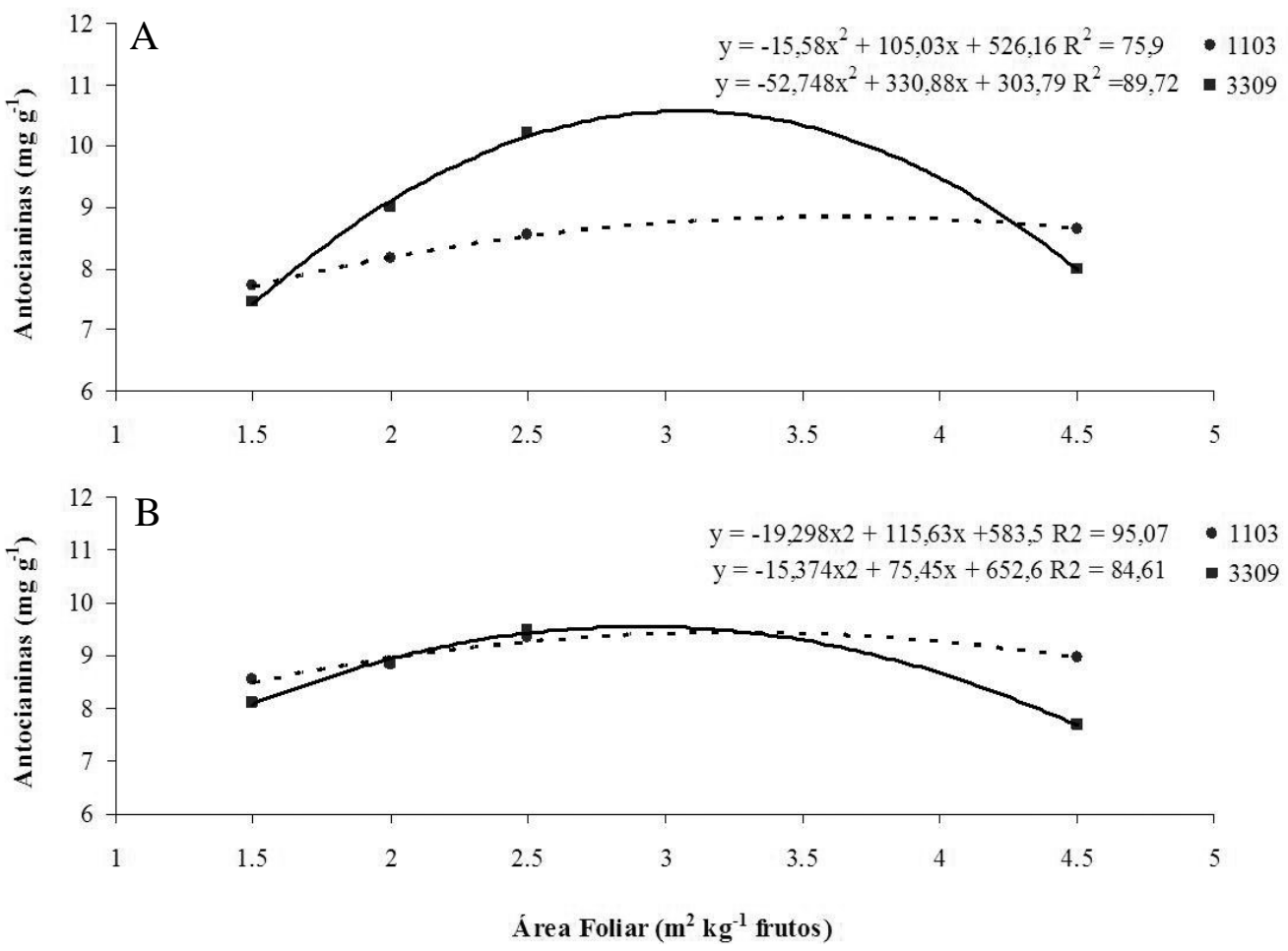

FIGURA 3 - Variação do teor de antocianinas ( $\mathrm{mg} \mathrm{kg}^{-1}$ ) da uva 'Merlot' (Vitis vinifera L.) sobre os portaenxertos 'Paulsen 1103' e 'Couderc 3309', submetida a diferentes níveis de desponte, nos ciclos de 2005-2006 (A) e 2006-2007 (B). Lages-SC, 2008.
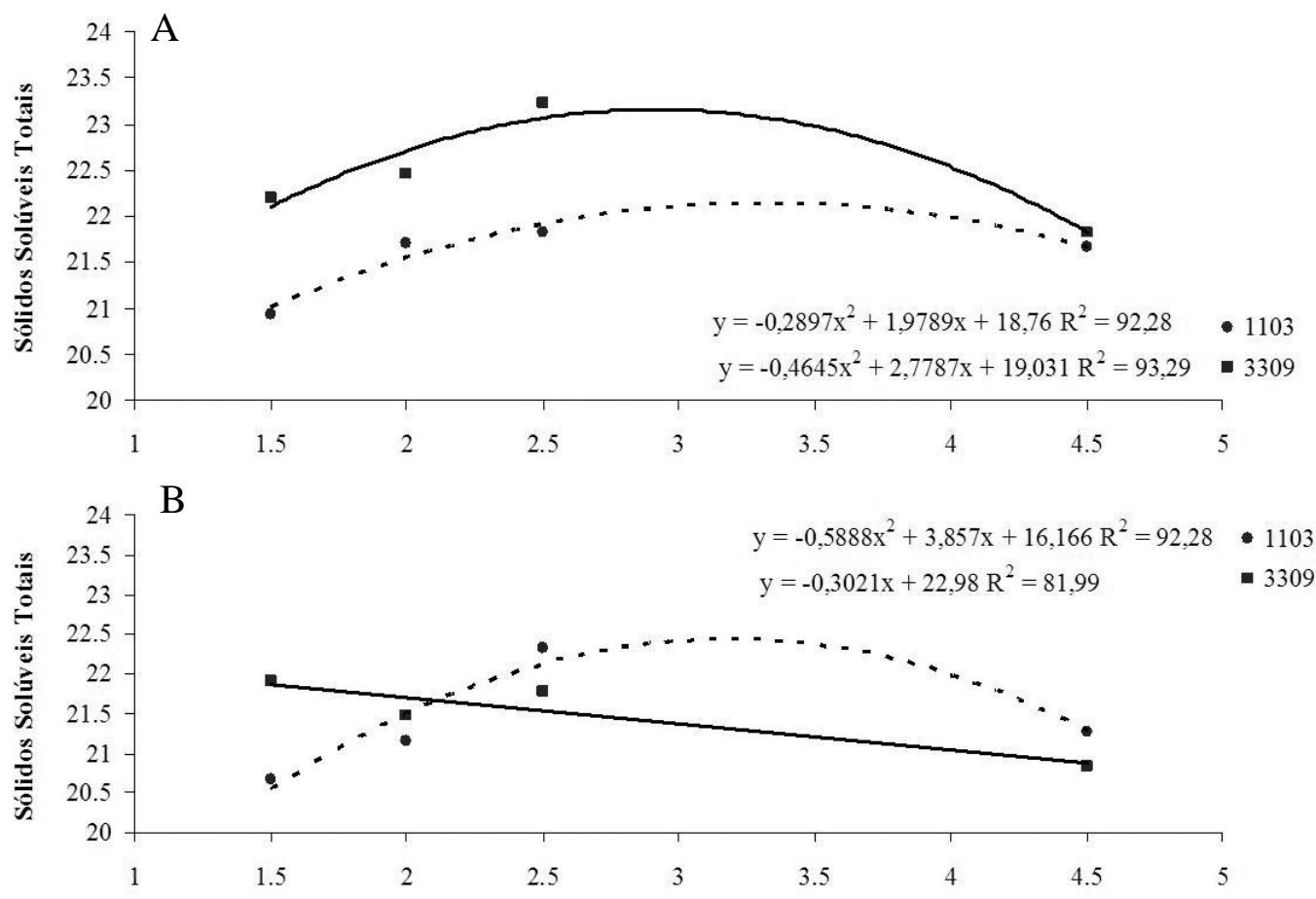

Área Foliar $\left(\mathrm{m}^{2} \mathrm{~kg}^{-1}\right.$ frutos $)$

FIGURA 4 - Variação do Brix da uva 'Merlot' (Vitis vinifera L.) sobre os porta-enxertos 'Paulsen 1103' e Coudere 3309', submetida a diferentes níveis de desponte, nos ciclos de 2005-2006 (A) e 2006-2007 (B). Lages-SC, 2008. 
TABELA 1 - Características dos frutos de uva cv. Merlot enxertado sobre 'Paulsen 1103’ e 'Couderc 3309' nos ciclos 2005/06 e 2006/07. Lages-SC, 2008.

\begin{tabular}{|c|c|c|c|c|}
\hline & Ciclo & 1103 & 3309 & C.V. (\%) \\
\hline \multirow{2}{*}{$\begin{array}{l}\text { Antocianinas } \\
\left(\mathrm{mg} \mathrm{g}^{-1}\right)\end{array}$} & $2005 / 06$ & 8,26 a & 8,66 a & 10,75 \\
\hline & 2006/07 & $8,92 \mathrm{a}$ & 8,54 a & 7,01 \\
\hline \multirow{2}{*}{ pH } & $2005 / 06$ & $3,91 \mathrm{a}$ & $3,78 \mathrm{a}$ & 3,54 \\
\hline & 2006/07 & 3,53 a & 3,46 a & 1,9 \\
\hline \multirow{2}{*}{${ }^{\circ}$ Brix } & $2005 / 06$ & $21,52 \mathrm{~b}$ & 22,42 a & 2,28 \\
\hline & 2006/07 & $21,36 \mathrm{a}$ & 21,49 a & 2,79 \\
\hline \multirow{2}{*}{$\begin{array}{l}\text { Polifenóis } \\
\text { (IPT) }\end{array}$} & $2005 / 06$ & $45,42 \mathrm{a}$ & 45,83 a & 7,32 \\
\hline & $2006 / 07$ & 44,72 a & 45,86 a & 4,15 \\
\hline \multirow{2}{*}{$\begin{array}{l}\text { Diâmetro de } \\
\text { Baga (mm) }\end{array}$} & $2005 / 06$ & $7,8 \mathrm{a}$ & $7,5 \mathrm{~b}$ & 2,09 \\
\hline & 2006/07 & 11,17 a & $11,34 \mathrm{a}$ & 3,91 \\
\hline \multirow{2}{*}{$\begin{array}{l}\mathbf{N}^{\circ} \text { Bagas } \\
\text { Cacho }\end{array}$} & $2005 / 06$ & 121,33 а & 12,77 a & 13 \\
\hline & $2006 / 07$ & $107,5 \mathrm{a}$ & $117,75 \mathrm{a}$ & 18,4 \\
\hline \multirow{2}{*}{ Peso Cacho (g) } & $2005 / 06$ & 159,81 a & 163,18 a & 13,03 \\
\hline & 2006/07 & $132,32 \mathrm{~b}$ & $190,05 \mathrm{a}$ & 24,9 \\
\hline \multirow{2}{*}{$\begin{array}{l}\text { Comprimento } \\
\text { Cacho }(\mathbf{c m})\end{array}$} & $2005 / 06$ & $18,13 \mathrm{a}$ & $17,81 \mathrm{a}$ & 9,45 \\
\hline & $2006 / 07$ & $18,89 \mathrm{a}$ & 19,69 a & 5,96 \\
\hline
\end{tabular}

*Médias seguidas de letras distintas na linha diferem significativamente, pelo teste de Tukey, com 5\% de probabilidade de erro.

\section{CONCLUSÕES}

1-É possível aumentar o conteúdo de açúcar nas bagas e o conteúdo de antocianinas, por meio de um desponte moderado, que conserve uma área foliar de 3,4 $\mathrm{m}^{2} \mathrm{~kg}^{-1} \mathrm{de}$ uva para as plantas enxertadas sobre 'Paulsen 1103' e 3,0 $\mathrm{m}^{2} \mathrm{~kg}^{-1}$ de uva para 'Couderc 3309'.

2-Os diferentes porta-enxertos não interferiram nos compostos fenólicos dos frutos da cv. Merlot. No ciclo de 2005/06, 'Couderc 3309’ induziu a produção de frutos da cv. Merlot com maior conteúdo de sólidos solúveis totais, e no ciclo de 2006/07, induziu a produção cachos mais pesados.

\section{REFERÊNCIAS}

BONIN, V.; BRIGHENTI, E. Aspectos climáticos e produção de vinhos finos na serra catarinense. In: ENCONTRO NACIONAL SOBRE FRUTICULTURA DE CLIMA TEMPERADO, 9., 2006, Fraiburgo. Anais... Fraiburgo: Epagri , 2006. 368 p.

BONIN, V.; BRIGHENTI, E. Situação atual e tendências da vitivinicultura na região de São Joaquim. In: SEMINNÁRIO NACIONAL SOBRE FRUTICULTURA DE CLIMA TEMPERADO, 6., 2005. São Joaquim. Resumos de palestras... São Joaquim: RisQ Editora e Gráfica, 2005. 117 p.
CLÍMACO, P.; LOPES, C.M.; CARNEIRO, L.C.; CASTRO, R. Efeito da casta e do porta-enxerto no vigor e na produtividade da videira.Ciência Técnica Vitivinícola, Dois Portos, v.18. p.1-14, 2003.

FICAGNA, P.R. Efeito do manejo do dossel vegetativo na qualidade da uva 'Merlot' produzida na serra catarinense. 2008. 89 f. Dissertação (Mestrado em Produção Vegetal) - Centro de Ciências Agroveterinárias, Universidade do Estado de Santa Catarina. Lages, 2008.

FREGONI, M. Viticoltura di qualitá. Verona: Edizione I’Informatore Agrário, 1998. 707p.

GIL, G.F.; PSZCZÓLKOWSKI, P. Viticultura: fundamentos para optimizar producción y calidad. Santiago: Ediciones Universidad Católica de Chile, 2007. 535 p.

GLORIES, Y. La couleur des vins rouges : les equilibres des anthocyanes et des tanins du Vin. Bordeaux: Actualités, 1998. 417 p.

ILAND, P.; BRUER, N.; EDWARDS, G.; WEEKS, S.; WILKES, E. Chemical analyses of grapes and wine: techniques and concepts. Adelaide: Tomy Kitchener Printigs, 2004. 110 p. 
INTRIERI, C.; PONI, S. Integrated evolution of trellis training systems and machines to improve grape quality and vintage quality of mechanized Italian vineyards. American Journal of Enology and Viticulture, Davis, v.46, p.116-127, 1995.

INTRIERI, C.; PRATELLA, F.; PONI, S.; FILIPETTI, I. Trimmer : nuova potatrice polivalente semplificata per vigneti. L'Informatore Agrario, Verona, v. 51, n.38, p.61-69. 1995.

JACKSON, D.I.; LOMBARD, P.B. Environmental and management practices affecting grape composition and wine quality - A review. American Journal of Enology and Viticulture, Davis, v.44, p.409- 430, 1993.

KOBLET, W. Effectiveness of shoot topping and leaf removal as a means of improving quality. Acta Horticulturae, Wageningen, v. 206, p.141-155, 1987.

MACHADO, M. P.; MAYER, J. L. S.; RITTER, M.; BIASI, L. A. Ácido indolbutírico no enraizamento de estacas semilenhosas do porta-enxerto de videira 'VR043-43' (Vitis vinifera x Vitis rotundifolia). Revista Brasileira de Fruticultura, Jaboticabal, v. 27, n.3, p.476 - 479, 2005.

MAIN, G.; MORRIS, J.; STRIEGLER, K. Rootstock effects on Chardonel productivity, fruit and wine composition. American Journal of Enology and Viticulture, Davis, v.53, p.37 - 40, 2002.

MANDELLI, F.; MIELE, A.; RIZZON, L. A.; ZANUS, M. C. Efeito da poda verde na composição físico-química do mosto da uva Merlot. Revista Brasileira de Fruticultura, Jaboticabal, v. 30, n.3, p.667 - 674, 2008 .

MARTINEZ de TODA, F. Evaluation method of the parasitic apical parts of shoots in Vitis vinifera. Vitis, Sielbeldingen, v.21, p.217-222, 1982.
MAY, P.Flowering and fruitset in grapevines. Adelaide: Lythum Press Pty, 2004. 120p.

OLLAT, N. J. P.; TANDONNET, M.; LAFONTAINE, H. R. SCHULTZ. Short and long term effects of three rootstocks on Cabernet Sauvignon vine behaviour and wine quality. Acta Horticulturae, Wageningen, v. 617, p.95-99, 2003.

PINKERTON, J.N.; VASCONCELOS, M.C.; SAMPAIO, T.L.; SHAFFER, R.G. Reaction of grape rootstocks to ring nematode Mesocriconema xenoplax. American Journal of Enology and Viticulture, Davis, v. 56, p.377 - 385, 2005.

REYNOLDS, A.G.; MOLEK, T.; de SAVIGNY, C. Timing of shoot thinning in Vitis vinifera: impacts on yield and fruit composition variables. American Journal of Enology and Viticulture, Davis, v. 56, p.343-356, 2005.

REYNOLDS, A.G.; WARDLE, D.A. Rootstocks impact vine performance and fruit composition of grapes in British Columbia. HortTechnology, Stanford, v. 11, p.419-427, 2001.

RIBÉREAU-GAYON, J.; PEYNAUD, E.; RIBÉREAU-GAYON, P.; SUDRAUD, P.Traité d'oenologie: sciences et techniques du Vin. Paris: Dunod, 1982. v.1, 645p.

RIBÉREAU-GAYON, P.; DUBORDIEU, D.; DONÈCHE, B.; LONVAUD, A. Traide d'enologie: microbiologie du Vin: vinifications. Paris: Editorial Dunod, 1998. 617 p.

SILVA, L. C.; KRETZSCHMAR, A. A.; RUFATO, L.; BRIGHENTI, A. F.; SCHLEMPER, C. Níveis de produção em vinhedos de altitude da cv. Malbec e seus efeitos sobre os compostos fenólicos. Revista Brasileira de Fruticultura, Jaboticabal, v. 30, n.3, p.675- 680, 2008 . 